\title{
In vivo generation and regeneration of $\beta$ cells in zebrafish
}

\author{
Bingyuan Yang, Brittney A. Covington and Wenbiao Chen *
}

\begin{abstract}
The pathological feature of diabetes, hyperglycemia, is a result of an inadequate number and/or function of insulin producing $\beta$ cells. Replenishing functional $\beta$ cells is a strategy to cure the disease. Although $\beta$-cell regeneration occurs in animal models under certain conditions, human $\beta$ cells are refractory to proliferation. A better understanding of both the positive and the negative regulatory mechanisms of $\beta$-cell regeneration in animal models is essential to develop novel strategies capable of inducing functional $\beta$ cells in patients. Zebrafish are an attractive model system for studying $\beta$-cell regeneration due to the ease to which genetic and chemical-genetic approaches can be used as well as their high regenerative capacity. Here, we highlight the current state of $\beta$-cell regeneration studies in zebrafish with an emphasis on cell signaling mechanisms.
\end{abstract}

\section{Background}

An absolute or relative deficiency of functional insulin producing $\beta$ cells is the pathological feature of both types of diabetes (Weir et al., 1990). Although the disease conditions can be managed by a number of drugs including insulin, insulin sensitizers, and glucose reabsorption inhibitors, current treatments are insufficient to prevent diabetic complications and can cause side effects, even when closely followed (Pothineni \& M. J., 2015; Corathers et al., 2013). Restoring functional $\beta$-cell mass may cure both type 1 and type 2 diabetes. Indeed, transplanting cadaveric islets gives recipients several years of insulin independence (Shapiro, 2000). The scarcity of compatible cadaveric donors and lifelong immune suppression limit its broad application. A heavily investigated alternative source is $\beta$ cells derived from human embryonic stem cells or induced pluripotent stem cells (Rezania et al., 2012; Pagliuca et al., 2014; Benthuysen et al., 2016). Despite tremendous progress, these $\beta$-like cells are still inferior to $\beta$ cells from donors (Tremmel et al., 2019). Even if fully functional $\beta$ cells can be generated in mass quantities, their preservation after

\footnotetext{
* Correspondence: Wenbiao.chen@vanderbilt.edu

Department of Molecular Physiology \& Biophysics, Vanderbilt University

School of Medicine, 2215 Garland Avenue, Nashville, TN 37232, USA
}

transplantation may still require immunosuppression. An alternative to in vitro $\beta$-cell production is induction of endogenous regeneration (Aguayo-Mazzucato \& BonnerWeir, 2018). Unlike in vitro generated $\beta$-like cells, in vivo generated $\beta$ cells situate in their natural environment, integrate into the intricate paracrine regulatory network in the islet, and deliver insulin directly to the portal vein. As such, they will likely function better. Recent studies in animal models suggest that in vivo $\beta$-cell regeneration is a viable approach to replenish $\beta$-cell mass in diabetic models (Aguayo-Mazzucato \& Bonner-Weir, 2018).

Pancreatic $\beta$-cell regeneration occurs physiologically in conditions of increased insulin demand such as pregnancy (Toselli et al., 2014; Kim et al., 2010; Karnik et al., 2007; Parsons et al., 1992) and obesity (Yamamoto et al., 2017; Bonner-Weir, 2000; Liu et al., 2017). Regeneration also occurs in experimentally induced conditions of insufficient insulin function, such as partial pancreatectomy (Togashi et al., 2014; Noèlia \& Eduard, 2014), $\beta$ cell ablation (Cheng et al., 2015; Thorel et al., 2010), and insulin receptor antagonist treatment (Jiao et al., 2014). Three general mechanisms of in vivo $\beta$-cell regeneration have been reported in animal models: self-replication or proliferation, neogenesis or progenitor differentiation, and transdifferentiation (Aguayo-Mazzucato \& Bonner- 
Weir, 2018). Proliferation refers to the generation of new $\beta$ cells from existing ones by cell division. It is the predominant mode of $\beta$-cell expansion from late gastrulation to adulthood in rodents (Dor et al., 2004; Teta et al., 2007). Neogenesis refers to the generation of $\beta$ cells from endocrine progenitors. This occurs during development as well as in adults (Bonner-Weir et al., 2012; Huising et al., 2018). Transdifferentiation refers to $\beta$-cell production from differentiated non- $\beta$ cells, usually from a cell type of related lineage such as pancreatic endocrine cells, hepatocytes, and intestinal endocrine cells. It occurs in certain conditions such as severe $\beta$-cell depletion and under some drug treatments (Thorel et al., 2010; Chera et al., 2014; Lee et al., 2018). Although evidence for all 3 mechanisms of $\beta$-cell regeneration exists (Bonner-Weir et al., 2010; Inada et al., 2008; Bouwens et al., 1994), it is generally believed that proliferation is the predominant mechanism (Dor et al., 2004; Teta et al., 2007). However, with advance of age, the capacity of $\beta$-cell proliferation and regeneration rapidly declines (Perl et al., 2010; Chen et al., 2011; Swenne, 1983). A recent finding revealed that the decline is accompanied by an increase of DNA methylation in $\beta$ cells (Avrahami et al., 2015).

Compared to rodents, adult human $\beta$ cells are resistant to proliferation. Once reaching a peak by early adulthood, human $\beta$-cell mass remains steady with very slow turnover (Butler et al., 2003; Gregg et al., 2012; Kassem et al., 2000). However, evidence of adult islet plasticity in response to insulin resistance exists (Mezza et al., 2019). Attempts to enhance human $\beta$-cell proliferation have been hindered by inadequate knowledge of the signaling pathways that promote cell cycle progression and prevent cell cycle reentry (Bernal-Mizrachi et al., 2014; Kulkarni et al., 2012; Stewart et al., 2015). What causes the resistance of human $\beta$-cell proliferation is not known. Thus, it is of paramount importance to identify signaling pathways that can specifically activate $\beta$-cell proliferation as well as pathways that confer its mitotic resistance for developing treatment targeting these pathways.

Zebrafish have been extensively used for understanding vertebrate biology and human diseases. This is due to many experimental advantages the model possesses. It is highly tractable genetically because of fecundity and oviparous reproduction. Highly efficient mutagenesis and transgenesis can be achieved with minimal training and commonly available reagents and equipment. As such, a large number of mutant and transgenic lines are available at nominal cost from various resource centers. Rapid development of translucent embryos makes zebrafish a favorable model organism for research, as many developmental events can be directly visualized. The small size of the embryo/larvae makes them compatible with chemical screening as they can be housed in microtiter plates for treatment and the anatomical or behavioral results can be easily observed. In addition to developmental biology, zebrafish have been increasingly used for modeling human diseases for mechanistic investigations and drug development (Lam Pui-Ying, 2019).

The zebrafish pancreas exhibits a remarkable capacity for regeneration (Delaspre et al., 2015; Ghaye et al., 2015; Moss et al., 2009). Recent findings in zebrafish $\beta$ cell regeneration have helped us understanding signaling pathways and transcription factors involved in $\beta$-cell neogenesis, transdedifferentiation and proliferation (Fig. 1). We will review these studies based on the methods employed to trigger $\beta$-cell formation (Table 1).

\section{A primer on zebrafish $\boldsymbol{\beta}$-cell development}

The zebrafish and mammalian pancreas show striking similarities in the molecular control of development, cellular and subcellular architecture, and physiological function (Pauls et al., 2007; Pack et al., 1996; Kinkel \& Prince, 2009; Parsons et al., 2009). Like mammals, the zebrafish pancreas derives from the dorsal and ventral buds of $p d x 1$-expressing foregut endoderm cells. The principal islet is formed at $24 \mathrm{~h}$ post-fertilization (hpf) by the coalescence of scattered endocrine cells from the first wave of differentiation in the dorsal bud that emerges before $18 \mathrm{hpf}$ (Wang et al., 2011; Biemar et al., 2001; Kimmel et al., 2011). The first wave of $\beta$ cells are mitotically quiescent and functionally immature (Hesselson et al., 2009). The principle islet undergoes further expansion

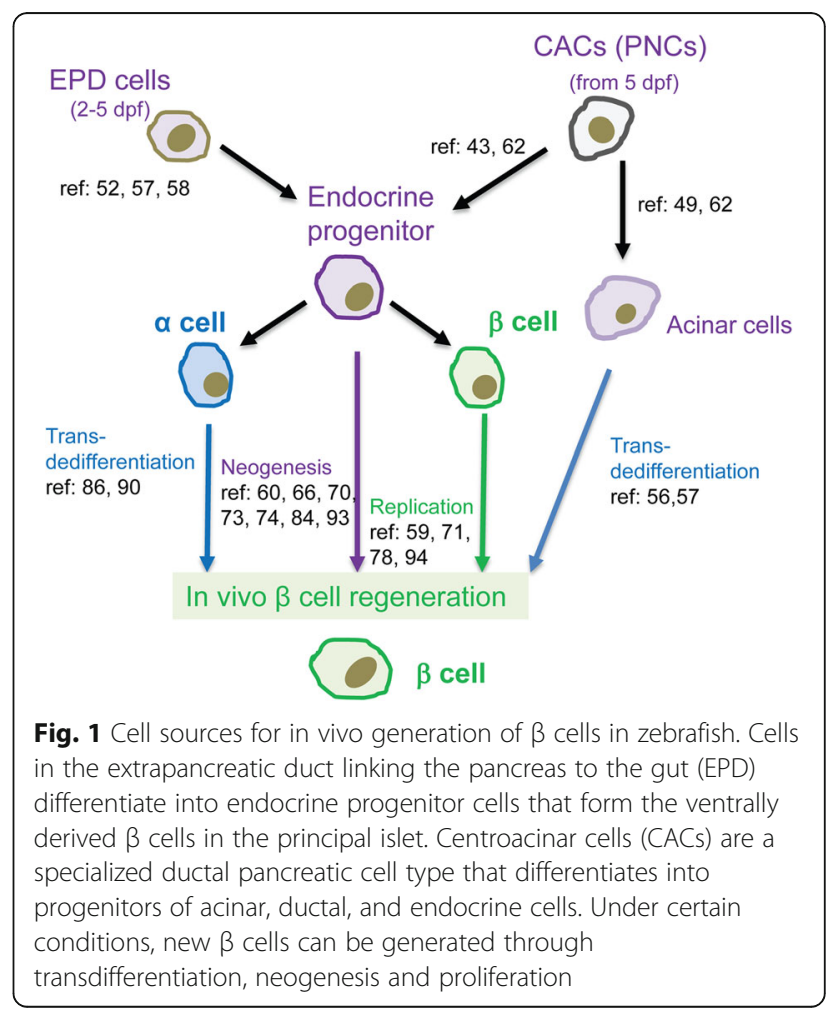




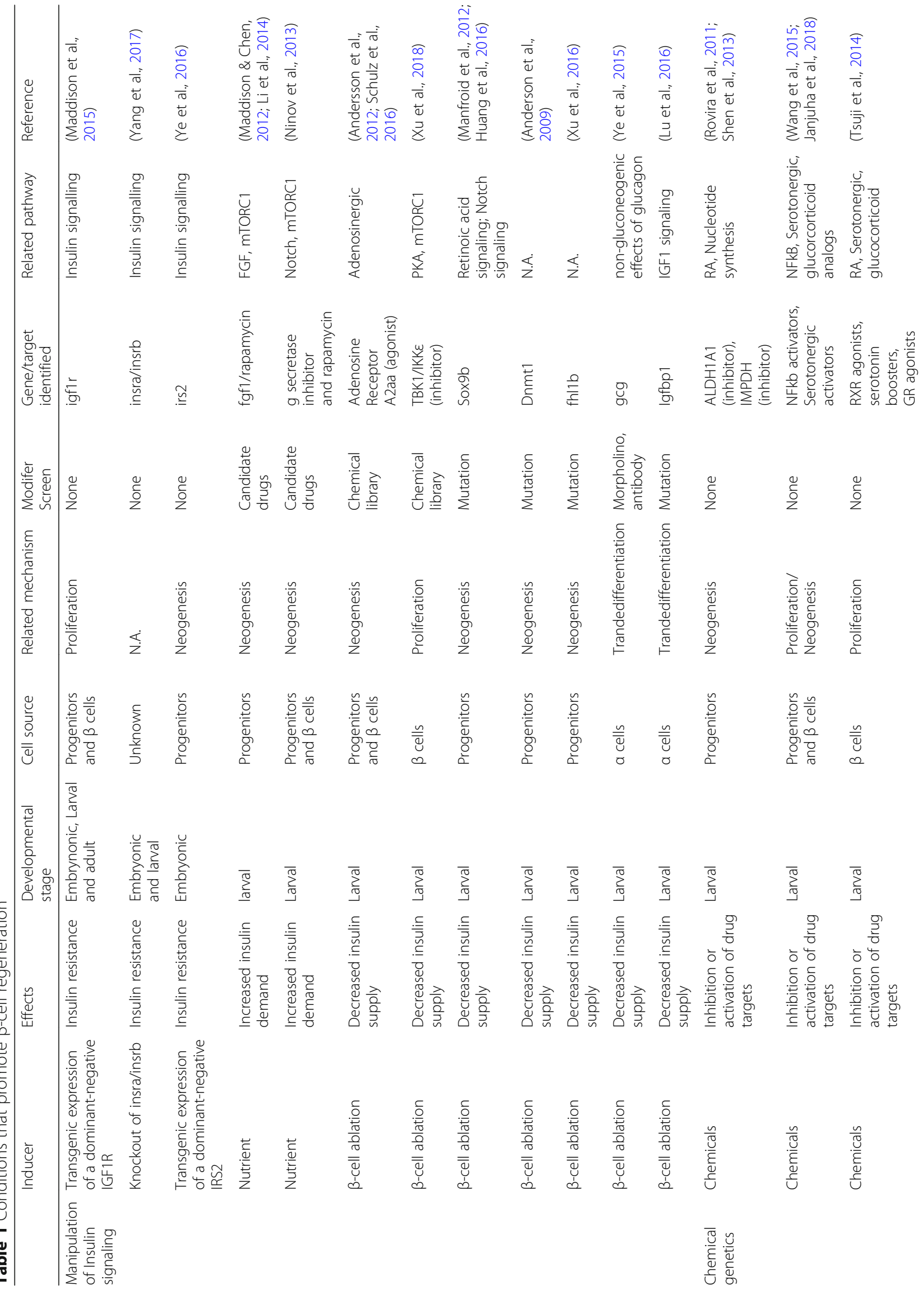




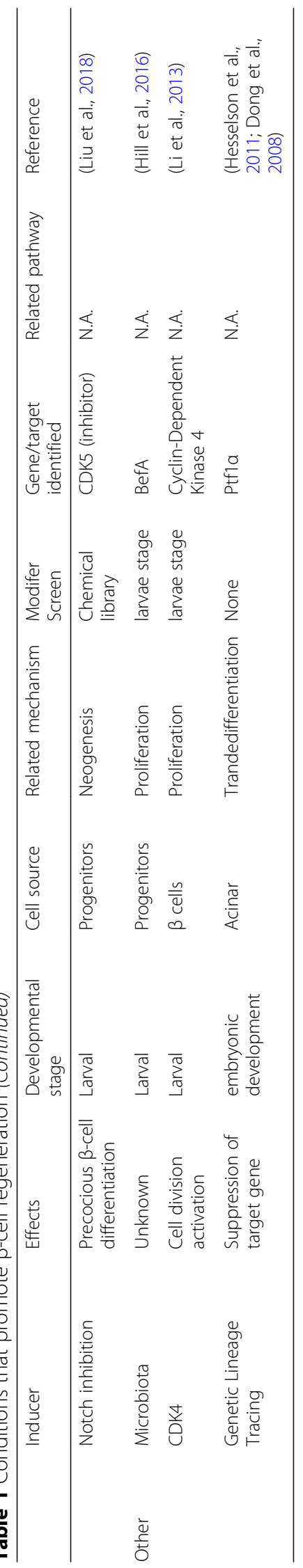


with endocrine cells from the second wave of differentiation starting at $40 \mathrm{hpf}$ from the ventral bud-derived cells (Hesselson et al., 2009), which also gives rise to acinar and ductal cells (Field et al., 2003). However, suppression of Ptfla activity during pancreatic development induces acinar to endocrine conversion (Hesselson et al., 2011; Dong et al., 2008). The principal islet continues to expand with endocrine cells differentiated from the FGF-responsive extrapancreatic duct (EPD) at the head of the pancreas between 2 to 5 days postfertilization (dpf) (Kimmel et al., 2011; Chung et al., 2010; Dong et al., 2007), and secondary islets form after $5 \mathrm{dpf}$ from endocrine progenitors derived from the pancreatic Notch-responsive cells (PNCs) in the intrapancreatic ductal cells (IPDs) as the pancreas expands caudally (Parsons et al., 2009; Wang et al., 2011), as well as from $\beta$-cell proliferation (Ninov et al., 2013; Tsuji et al., 2014). Whether EPD continues to contribute to principal islet expansion is unknown. Inhibition of Notch signaling causes precocious endocrine differentiation and secondary islet formation (Parsons et al., 2009). Modulating the duration and/or extent of Notch signaling inhibition can uncouple amplification and differentiation of the progenitor (Ninov et al., 2012). In addition to endocrine progenitors, these specialized ductal PNCs are also the source of other ductal cells, acinar cells, and centroacinar cells (CACs) in adults, and are morphologically similar to CACs (Delaspre et al., 2015). CACs are situated at the tips of the pancreatic duct inside the acinus and contribute to endocrine cell regeneration after $\beta$-cell ablation or partial pancreatectomy (Wang et al., 2011; Beer et al., 2016).

It is believed that $\beta$-cell proliferation is the predominant mechanism for expanding adult $\beta$ cells in mice (Dor et al., 2004; Stamateris et al., 2013; Dor, 2006). However, in zebrafish larvae, $\beta$-cell proliferation is not predominant and is dependent on developmental stages and physiological states (Singh et al., 2017). Most advantages of zebrafish over other vertebrate models only hold true in larvae. Early larval zebrafish have only one (principal) islet. This allows rapid analysis of cell number changes. Combined with other already discussed advantages, zebrafish have allowed several groups to identify small molecule modulators and molecular mechanisms of $\beta$-cell regeneration (Andersson et al., 2012; Wang et al., 2015; Moon et al., 2020). Nevertheless, the compounds identified in zebrafish may provide new therapies and help identify new therapeutic targets for $\beta$-cell regeneration therapy in patients. Here, we highlight some of these studies according to the stimulus of $\beta$-cell generation. We emphasize the signaling mechanisms leading to $\beta$-cell formation in these models, which provide a potential avenue for the development of anti-diabetic drugs through in vivo $\beta$-cell regeneration.

\section{$\beta$-Cell induction by physiological stimuli Insulin signaling}

The $\beta$-cell deficit of Type 2 diabetics may be due to insufficient $\beta$-cell production during development and/or defective compensatory $\beta$-cell production in response to insulin resistance (Costes et al., 2013). Therefore, understanding physiological $\beta$-cell generation is critical for comprehension, prediction, and possibly prevention of diabetes susceptibility.

A key regulator of $\beta$-cell number is insulin signaling. Insufficient insulin signaling increases both $\beta$-cell number and function to maintain glucose homeostasis (Maddison et al., 2015; Yang et al., 2017; Ye et al., 2016). Defect or breakdown of the compensatory response is the root cause of type 2 diabetes. Although the mechanisms of this compensatory response are not fully delineated, both $\beta$-cell extrinsic and intrinsic mechanisms have been proposed (Mezza et al., 2019). The compensatory response is conserved in zebrafish (Yang et al., 2017; Ye et al., 2016). For example, elimination of the insulin receptor by concurrent inactivation of both insulin receptors (insra and insrb) leads to an increase of $\beta$ cells (Yang et al., 2017). This compensatory response occurs as early as the first wave of $\beta$-cell differentiation. Blocking insulin activity by knocking down insra, expressing a dominant-negative IRS2, or exposure to the AKT2 inhibitor from early embryogenesis all cause a significant increase of $\beta$ cells as early as $24 \mathrm{hpf}$ at the expense of $\alpha$-cell differentiation (Ye et al., 2016). Similarly, suppressing insulin signaling only in skeletal muscle, a major insulin sensitive tissue, also leads to an increase of $\beta$-cell number (Maddison et al., 2015). In this case, the increase occurs later and more gradually, likely due to the tissue restricted insulin resistance. The increase of $\beta$ cells is at least in part due to proliferation (Maddison et al., 2015).

\section{Nutrient stimulated $\beta$-cell generation}

$\beta$ cells are nutrient sensors. Nutrient ingestion stimulates insulin secretion and increases insulin demand. Two groups have demonstrated that nutrients stimulate $\beta$-cell production in larval zebrafish (Maddison \& Chen, 2012; Ninov et al., 2013). By culturing 6 or 18 dpf larvae in 5\% fresh chicken egg yolk for $8 \mathrm{~h}$, Maddison and Chen showed a rapid increase of $\beta$ cells by the end of culture. Co-incubation with 5-ethynyl-2'-deoxyuridine (EdU) did not identify proliferating $\beta$ cells, indicating that the increase is due to neogenesis (Maddison \& Chen, 2012). The neogenesis is caused by persistent stimulation of existing $\beta$ cells since activation of the nutrient-secretion coupling system either pharmacologically or genetically 
also increased $\beta$-cell production (Li et al., 2014). This suggests a non-cell autonomous mechanism in which existing $\beta$ cells emit a signal to induce differentiation of the yet unidentified responding progenitors, likely the EPD cells, PNCs or its descendants. Using candidate drug screen, the group identified FGF1 as the $\beta$-cell signal responsible for induction of $\beta$-cell neogenesis ( $\mathrm{Li}$ et al., 2016). Reexpression of human FGF1 in $\beta$ cells rescues the defective response in $f g f 1-/-$ fish. Mechanistically, persistent stimulation of $\beta$ cells causes mild ER stress, which triggers FGF1 secretion ( $\mathrm{Li}$ et al., 2016). Ninov and colleagues demonstrated nutrient-dependent $\beta$-cell production in older zebrafish larvae (Ninov et al., 2013). At $15 \mathrm{dpf}$ when the larvae were fed with a high calorie diet, more secondary islets formed than in larvae fed with a low-calorie diet. The $\beta$ cells were generated from NRCs and at least in part from proliferation. Both neogenesis and proliferation require nutrients and can be inhibited by fasting or rapamycin (Ninov et al., 2013), indicating a role for mTORC1 activity. It is likely overnutrition or a high calorie diet also induces neogenesis and proliferation in adults, but such studies have not been reported.

\section{Microbiota}

The gut microbiota has been shown to influence vertebrate development and physiology (Lynch \& Pedersen, 2016). Zebrafish gut microbiota is established after hatching and can be suppressed using antibiotics (Rawls et al., 2004). Recently, the Guillemin lab reported an interesting finding that demonstrated a role for the microbiota in early pancreatic $\beta$-cell development (Hill et al., 2016). Germ-free zebrafish have fewer $\beta$ cells than the control. The $\beta$-cell number can be normalized by the addition of bacteria that express a conserved previously undescribed secreted protein, BefA ( $\beta$-Cell Expansion Factor A). Intriguingly, when added in the medium, recombinant BefA, a protein of 261 residues, could restore $\beta$-cell number in germ-free larvae to control levels. BefA homologs from the human gut microbiome display similar activity in zebrafish. BefA seems to induce more EdU-positive $\beta$ cells indicative of proliferation, although EdU was applied for $48 \mathrm{~h}$ and the labeling could be from endocrine progenitor cells (Hill et al., 2016). It will be interesting to determine whether the activity requires the entire protein or only a fragment. Equally interesting is the BefA signaling mechanism. For example, it may stimulate $\beta$ cells directly or cause insulin resistance in other tissues.

\section{Chemical induced $\beta$-cell generation}

While nutrient-induced $\beta$-cell generation is important for establishing robust $\beta$-cell mass before the onset of diabetes, it has limited therapeutic potential. By contrast, drug-induced in vivo $\beta$-cell generation has tremendous therapeutic potential. A number of chemical screens to induce $\beta$-cell generation in zebrafish have been reported (Andersson et al., 2012; Rovira et al., 2011; Shen et al., 2013). The Parsons lab uses precocious secondary islet formation as the readout for increased $\beta$-cell neogenesis (Rovira et al., 2011). By exposing larvae from $2.5 \mathrm{dpf}$ to $5 \mathrm{dpf}$ to more than 3000 compounds, they identified 6 hits. Two of the hits, DSF and MPA, have been approved for the treatment of alcohol abuse and immunosuppression, respectively. Further analysis demonstrated that DSF acts by suppressing retinoic acid synthesis while MPA acts by lowering cellular GTP levels by inhibiting inosine 5 '-monophosphate dehydrogenase (IMPDH) (Rovira et al., 2011). The Parsons and Mumm groups developed a high-throughput screen using signal intensity of an insulin promoter driven fluorescent protein in transgenic larvae as the readout (Wang et al., 2015). By exposing the transgenic larvae to individual compounds from 3 to 7 days of age, they identified 24 hits from over 3000 compounds. Some of the compounds induced precocious secondary islets, which suggests they promote neogenesis. Two NF-KB inhibitors are in this group, indicating suppression of NF-KB promotes $\beta$-cell differentiation. Other drugs specifically increased $\beta$-cell number without accelerating secondary islet formation. Several of these compounds activated the serotonergic signaling pathway and promoted $\beta$-cell proliferation (Wang et al., 2015).

Compounds that specifically promote $\beta$-cell differentiation are more desirable. It is well established that inhibition of Notch signaling in the Notch-responsive ductal cells promote endocrine progenitor differentiation, resulting in the production of all islet endocrine cell types (Parsons et al., 2009). By co-administering a Notch inhibitor along with more than 2000 compounds from 3 dpf to $5 \mathrm{dpf}$, Liu et al. identified a CDK5 inhibitor that specifically enhanced $\beta$-cell differentiation (Liu et al., 2018). Inhibition of CDK5 also enhanced $\beta$-cell differentiation in mouse islet explants, in mice with pancreatic ductal ligation, and in human iPS cells (Liu et al., 2018).

To identify compounds that promote $\beta$-cell proliferation directly, the Stainier lab adopted the FUCCI system to mark proliferating $\beta$ cells (Tsuji et al., 2014). They found that during the first 6 days of development $\beta$ cells are mitotically quiescent except for two stages, $36 \mathrm{hpf}$ and $144 \mathrm{hpf}$. By exposing embryos to more than 2000 compounds from 72 to $96 \mathrm{hpf}$, they identified 20 small molecules that enhance $\beta$-cell proliferation during the quiescent period. Of note, most of the compounds affect serotonin, retinoic acid or the glucocorticoids signaling pathway, with the latter two groups also promoting $\beta$ cell proliferation after ablation (Tsuji et al., 2014). The serotonergic pathway has been shown to mediate adult $\beta$-cell proliferation during pregnancy (Kim et al., 2010) 
and perinatal $\beta$-cell proliferation (Moon et al., 2020) in mice through HTR2B. The identification of the serotonergic pathway from two independent zebrafish screens further validates the relevance of this approach (Wang et al., 2015; Janjuha et al., 2018).

\section{Ablation-induced $\beta$-cell regeneration}

Type 1 diabetes results from complete or near complete $\beta$-cell loss. In zebrafish, complete or near complete $\beta$ cell loss by pancreatectomy or drug-induced killing causes robust $\beta$-cell regeneration (Delaspre et al., 2015; Moss et al., 2009; Andersson et al., 2012; Curado et al., 2007). These regenerated $\beta$ cells are from neogenesis, proliferation, and $\alpha$ - to $\beta$-cell transdifferentiation. Understanding the molecular mechanisms underlying this response may shed light on ways to induce $\beta$-cell regeneration in Type 1 diabetes patients, if autoimmunity can be controlled.

Several genes, sox $9 b$, dnmt $1, g c g$ and $f h 1 b$, have been found to play an important role in ablation-induced $\beta$ cell regeneration (Manfroid et al., 2012; Anderson et al., 2009; Ye et al., 2015; Li et al., 2009). Manfroid and colleagues found that ablation-induced $\beta$-cell regeneration is severely impaired in sox $9 b$ mutants. This is because Sox9b is critical for the formation of the PNCs and CACs (Manfroid et al., 2012; Huang et al., 2016). Anderson and colleagues found ablation-induced $\beta$-cell regeneration is surprisingly enhanced in dnmt1 mutant larvae, suggesting decreased DNA methylation promotes $\beta$-cell regeneration (Anderson et al., 2009). In mice, near complete $\beta$-cell ablation triggers $\alpha$ - or $\delta$ - to $\beta$-cell transdifferentiation (Thorel et al., 2010; Chera et al., 2014). However, the Anderson group showed that only $\alpha$ cells, but not $\delta$ cells, contributed to $\beta$-cell regeneration after $\beta$-cell ablation in zebrafish (Ye et al., 2015). Using a combination of pharmacological and morpholino antisense oligonucleotide-mediated knockdown approaches, they demonstrated that the $\alpha$-cell transdfferentiation was dependent on glucagon but independent of gluconeogenesis (Ye et al., 2015). This may explain the findings of $\mathrm{Li}$ and colleagues, who demonstrated that persistent killing of $\beta$ cells by insulin promoter-directed expression of diphtheria toxin A chain also decreased $\underline{\alpha}$ cells (Li et al., 2009). Lu et al. found that after $\beta$-cell ablation, igfbp1 expression is increased. Igfbp 1 could potently promote $\beta$-cell regeneration by triggering $\alpha$ - to $\beta$-cell transdifferentiation via inhibiting the IGF signaling pathway (Lu et al., 2016). This IGFBP1 function is conserved in mice and human islets ( $\mathrm{Lu}$ et al., 2016). Another gene that regulates $\beta$ cell neogenesis is $f h l 1 b^{91}$. fhl1b mutants have enhanced $\beta$-cell regeneration due to increased $p d x 1$ and neurod expression in the EPD (Xu et al., 2016).
Chemicals that promote $\beta$-cell regeneration after ablation may be exploited for novel drug development. Because pancreatectomy is labor-intensive and incompatible with chemical screens, all chemical screens used metronidazole (MTZ)-mediated ablation of $\beta$ cells expressing a fluorescent protein fusion of bacterial nitroreductase (NTR) (Curado et al., 2007; Pisharath et al., 2007). Ablation can be done easily by adding MTZ in the medium. The fluorescent protein also provides a marker for the ablation efficiency and a readout of the subsequent regeneration. Using this system, the Stainier group screened more than 7000 compounds and identified NECA as a compound that markedly increases $\beta$-cell regeneration (Andersson et al., 2012). It does so by activating adensosine GPCR signaling. Both neogenesis and proliferation contribute to $\beta$-cell regeneration. Although this compound only had a limited capacity to induce $\beta$-cell proliferation in larval zebrafish, it can potently induce $\beta$-cell proliferation in a streptozotocin (STZ)-induced mouse T1D model (Andersson et al., 2012). In addition, pharmacological and genetic disruption of the A2a receptor diminished $\beta$-cell proliferation during pregnancy in mice (Schulz et al., 2016). In another screen using a similar system, the Shin lab screened 75 compounds and identified BX795 as a stimulator of $\beta$-cell regeneration (Xu et al., 2018). Further analyses indicated that BX795 acts by inhibiting TBK1/IKKe. This finding led to the identification of an even more potent compound known to inhibit TBK1/IKKE, PIAA. PIAA primarily increased $\beta$-cell proliferation in zebrafish and a STZ-induced mouse T1D model. Further mechanistic studies revealed that PIAA inhibits TBK1/IKK $\varepsilon$ phosphorylation of PDE3, resulting in activation of PKA and its target mTORC1, leading to $\beta$-cell specific proliferation (Xu et al., 2018).

\section{Factors that limit $\beta$-cell proliferation}

Like in mammals, $\beta$-cell proliferation in zebrafish also declines with age (Janjuha et al., 2018). Comparing $\beta$ cells from younger and older zebrafish, aging islets exhibit signs of chronic inflammation (Janjuha et al., 2018). Further investigation indicates that $\beta$ cells with high NF-kB signaling proliferate significantly less compared to their neighbors with low activity. The cells with active NF-kB signaling also exhibit premature upregulation of socs2, an agerelated gene that inhibits $\beta$-cell proliferation (Janjuha et al., 2018). Another potential limitation of $\beta$-cell replication is insufficient activity of cyclin-dependent kinase 4 (CDK4). This may be due to age-dependent increased expression of cyclin-dependent kinase inhibitors in $\beta$ cells, such as p27 (Georgia \& Bhushan, 2006), p21 (Fatrai et al., 2006), and p16 (Helman et al., 2016), as observed in mice. By ectopically expressing in $\beta$ cells a mutant CDK4 $\left(\mathrm{CDK} 4^{\mathrm{R} 24 \mathrm{C}}\right)$ that is insensitive to inhibition by cyclindependent kinase inhibitors, $\beta$-cell number could be increased through enhanced proliferation (Li et al., 2013). 


\section{Conclusion}

Replenishment of new glucose-responsive $\beta$ cells is the best therapeutic approach to cure diabetes. Here, we summarized the recent advances in $\beta$-cell regeneration in vivo using the zebrafish model. Distinguishing the cell sources for in vivo generation of $\beta$ cells and understanding the mechanisms underlying these processes are of great importance for designing strategies to achieve a $\beta$ cell based cure.

\section{Perspective}

In vivo $\beta$-cell regeneration is a potential cure for both types of diabetes. However, there is still much that needs to be done before this strategy can be implemented. Continued drug screening efforts in zebrafish will likely contribute to its eventual success. In addition to screening larger compound libraries, future zebrafish studies should also address the toxicity and specificity of the identified compounds. Translation to humans should remain the focus. For any given compound that promotes $\beta$-cell regeneration in zebrafish, its efficacy and specificity should be assessed in rodents as some of the previous studies have done (Schulz et al., 2016; El Ouaamari et al., 2016). Except for these that promote neogenesis, the compounds should also be tested on human islets whenever possible. Since multiple pathways may be involved in limiting proliferation of, or transdifferentiation to, human $\beta$ cells, combined treatment of multiple compounds may be productive. Positive human islet data should pave the way for clinical trials and subsequent drug approval.

\section{Acknowledgements}

We thank members of the Chen lab for discussion.

\section{Authors' contributions}

BY, BC and WC wrote the paper. The author(s) read and approved the final manuscript.

\section{Funding}

DK117147, DK109407, Vanderbilt DRTC, and Vanderbilt University.

\section{Competing interests}

The authors declare that they have no competing interests.

Received: 26 February 2020 Accepted: 22 May 2020

Published online: 02 July 2020

\section{References}

Aguayo-Mazzucato C, Bonner-Weir S. Pancreatic $\beta$ Cell Regeneration as a Possible Therapy for Diabetes. Cell Metabolism. 2018;27:57-67. https://doi.org/10. 1016/j.cmet.2017.08.007.

Anderson RM, et al. Loss of Dnmt1 catalytic activity reveals multiple roles for DNA methylation during pancreas development and regeneration. Developmental Biology. 2009;334:213-23. https://doi.org/10.1016/j.ydbio. 2009.07.017.

Andersson $\mathrm{O}$, et al. Adenosine Signaling Promotes Regeneration of Pancreatic $\beta$ Cells In Vivo. Cell Metabolism. 2012;15:885-94. https://doi.org/10.1016/j.cmet. 2012.04.018.
Avrahami D, et al. Aging-Dependent Demethylation of Regulatory Elements Correlates with Chromatin State and Improved; Cell Function. Cell Metab. 2015;22:619-32. https://doi.org/10.1016/j.cmet.2015.07.025.

Beer RL, Parsons MJ, Rovira M. Centroacinar cells: At the center of pancreas regeneration. Developmental Biol. 2016;413:8-15. https://doi.org/10.1016/j. ydbio.2016.02.027.

Benthuysen JR, Carrano AC, Sander M. Advances in $\beta$ cell replacement and regeneration strategies for treating diabetes. J Clin Invest. 2016;126:3651-60. https://doi.org/10.1172/JCl87439.

Bernal-Mizrachi E, et al. Human $\beta$-Cell Proliferation and Intracellular Signaling Part 2: Still Driving in the Dark Without a Road Map. Diabetes. 2014;63:819-31. https://doi.org/10.2337/db13-1146.

Biemar F, et al. Pancreas Development in Zebrafish: Early Dispersed Appearance of Endocrine Hormone Expressing Cells and Their Convergence to Form the Definitive Islet. Dev Biol. 2001;230:189-203. https://doi.org/10.1006/dbio.2000.0103.

Bonner-Weir S. Life and Death of the Pancreatic $\beta$ Cells. Trends Endocrinology Metab. 2000;11:375-8. https://doi.org/10.1016/S1043-2760(00)00305-2.

Bonner-Weir S, et al. Beta-cell growth and regeneration: replication is only part of the story. Diabetes. 2010;59:2340-8. https://doi.org/10.2337/db10-0084.

Bonner-Weir S, et al. Islet neogenesis: a possible pathway for beta-cell replenishment. Rev Diabet Stud. 2012;9:407-16. https://doi.org/10.1900/RDS. 2012.9.407

Bouwens L, Wang R-N, Blay ED, Pipeleers DG, Klöppel G. Cytokeratins as Markers of Ductal Cell Differentiation and Islet Neogenesis in the Neonatal Rat Pancreas. Diabetes. 1994;43:1279-83. https://doi.org/10.2337/diab.43.11.1279.

Butler, A. E. et al. $\beta$-Cell Deficit and Increased $\beta$-Cell Apoptosis in Humans With Type 2 Diabetes. Diabetes 52, 102-110, doi:https://doi.org/10.2337/diabetes. 52.1.102 (2003)

Chen $\mathrm{H}$, et al. PDGF signalling controls age-dependent proliferation in pancreatic $\beta$-cells. Nature. 2011;478:349-55. https://doi.org/10.1038/nature10502.

Cheng $Y$, et al. Beta-cell regeneration from vimentin+/MafB+ cells after STZinduced extreme beta-cell ablation. Sci Rep. 2015;5:11703. https://doi.org/10. 1038/srep11703.

Chera $\mathrm{S}$, et al. Diabetes recovery by age-dependent conversion of pancreatic $\delta$ cells into insulin producers. Nature. 2014;514:503-7. https://doi.org/10.1038/ nature13633.

Chung W-S, Andersson O, Row R, Kimelman D, Stainier DYR. Suppression of Alk8mediated Bmp signaling cell-autonomously induces pancreatic beta-cells in zebrafish. Proc Nat Acad Sci United States America. 2010;107:1142-7. https:// doi.org/10.1073/pnas.0910205107.

Corathers SD, Peavie S, Salehi M. Complications of diabetes therapy. Endocrinol Metab Clin North Am. 2013;42:947-70. https://doi.org/10.1016/j.ecl.2013.06.005.

Costes S, Langen R, Gurlo T. Matveyenko, A. V. \& Butler, P. C. $\beta$-Cell failure in type 2 diabetes: a case of asking too much of too few? Diabetes. 2013;62:327-35. https://doi.org/10.2337/db12-1326.

Curado $S$, et al. Conditional targeted cell ablation in zebrafish: A new tool for regeneration studies. Developmental Dynamics. 2007;236:1025-35. https:// doi.org/10.1002/dvdy.21100.

Delaspre F, et al. Centroacinar Cells Are Progenitors That Contribute to Endocrine Pancreas Regeneration. Diabetes. 2015;64:3499-509. https://doi.org/10.2337/ db15-0153.

Dong PDS, Provost E, Leach SD, Stainier DYR. Graded levels of Ptf1a differentially regulate endocrine and exocrine fates in the developing pancreas. Genes Dev. 2008;22:1445-50. https://doi.org/10.1101/gad.1663208.

Dong PDS, et al. Fgf10 regulates hepatopancreatic ductal system patterning and differentiation. Nature Genet. 2007;39:397-402. https://doi.org/10.1038/ng1961.

Dor Y. $\beta$-cell proliferation is the major source of new pancreatic $\beta$ cells. Nat Clin Pract Endocrinol Metab. 2006;2:242-3. https://doi.org/10.1038/ ncpendmet0187.

Dor Y, Brown J, Martinez OI, Melton DA. Adult pancreatic $\beta$-cells are formed by self-duplication rather than stem-cell differentiation. Nature. 2004;429:41-6. https://doi.org/10.1038/nature02520.

El Ouaamari A, et al. SerpinB1 Promotes Pancreatic $\beta$ Cell Proliferation. Cell metabolism. 2016;23:194-205. https://doi.org/10.1016/j.cmet.2015.12.001.

Fatrai S, et al. Akt Induces $\beta$-Cell Proliferation by Regulating Cyclin D1, Cyclin D2, and p21 Levels and Cyclin-Dependent Kinase-4 Activity. Diabetes. 2006;55: 318-25. https://doi.org/10.2337/diabetes.55.02.06.db05-0757.

Field HA, Dong PDS, Beis D, Stainier DYR. Formation of the digestive system in zebrafish. ii. pancreas morphogenesis $\boldsymbol{i}_{\text {s. }}$. Developmental Biology. 2003;261: 197-208. https://doi.org/10.1016/S0012-1606(03)00308-7. 
Georgia S, Bhushan A. p27 Regulates the Transition of $\beta$-Cells From Quiescence to Proliferation. Diabetes. 2006;55:2950-6. https://doi.org/10.2337/db06-0249.

Ghaye AP, et al. Progenitor potential of nkx6.1-expressing cells throughout zebrafish life and during beta cell regeneration. BMC Biology. 2015;13:70. https://doi.org/10.1186/s12915-015-0179-4.

Gregg BE, et al. Formation of a human $\beta$-cell population within pancreatic islets is set early in life. J Clin Endocrinol Metab. 2012;97:3197-206. https://doi.org/ 10.1210/jc.2012-1206.

Helman A, et al. p16Ink4a-induced senescence of pancreatic beta cells enhances insulin secretion. Nature Medicine. 2016;22:412-20. https://doi.org/10.1038/ $\mathrm{nm} .4054$

Hesselson D, Anderson RM, Beinat M, Stainier DYR. Distinct populations of quiescent and proliferative pancreatic $\beta$-cells identified by HOTcre mediated labeling. Proc Nat Acad Sci. 2009;106:14896-901. https://doi.org/10.1073/ pnas.0906348106.

Hesselson D, Anderson RM, Stainier DYR. Suppression of Ptf1a Activity Induces Acinar-to-Endocrine Conversion. Curr Biol. 2011;21:712-7. https://doi.org/10. 1016/j.cub.2011.03.041.

Hill JH, Franzosa EA, Huttenhower C, Guillemin K. A conserved bacterial protein induces pancreatic beta cell expansion during zebrafish development. eLife. 2016:5:e20145. https://doi.org/10.7554/eLife.20145.

Huang $W$, et al. Sox9b is a mediator of retinoic acid signaling restricting endocrine progenitor differentiation. Developmental Biology. 2016;418:28-39. https://doi.org/10.1016/j.ydbio.2016.08.019.

Huising MO, Lee S, van der Meulen T. Evidence for a Neogenic Niche at the Periphery of Pancreatic Islets. BioEssays. 2018;40:1800119. https://doi.org/10. 1002/bies.201800119.

Inada A, et al. Carbonic anhydrase II-positive pancreatic cells are progenitors for both endocrine and exocrine pancreas after birth. Proc Nat Acad Sci. 2008; 105:19915-9. https://doi.org/10.1073/pnas.0805803105.

Janjuha, S. et al. Age-related islet inflammation marks the proliferative decline of pancreatic beta-cells in zebrafish. eLife 7, e32965, doi:https://doi.org/10.7554/ eLife.32965 (2018).

Jiao Y, Le Lay J, Yu M, Naji A, Kaestner KH. Elevated Mouse Hepatic Betatrophin Expression Does Not Increase Human $\beta$-Cell Replication in the Transplant Setting. Diabetes. 2014:63:1283-8. https://doi.org/10.2337/db13-1435.

Karnik SK, et al. Menin Controls Growth of Pancreatic B-Cells in Pregnant Mice and Promotes Gestational Diabetes Mellitus. Science. 2007;318:806-9. https:// doi.org/10.1126/science.1146812.

Kassem SA, Ariel I, Thornton PS, Scheimberg I, Glaser B. Beta-cell proliferation and apoptosis in the developing normal human pancreas and in hyperinsulinism of infancy. Diabetes. 2000;49:1325-33. https://doi.org/10.2337/diabetes.49.8.1325.

Kim H, et al. Serotonin regulates pancreatic beta cell mass during pregnancy. Nature Med. 2010;16:804-8. https://doi.org/10.1038/nm.2173.

Kimmel RA, Onder L, Wilfinger A, Ellertsdottir E, Meyer D. Requirement for Pdx1 in specification of latent endocrine progenitors in zebrafish. BMC Biology. 2011;9:75. https://doi.org/10.1186/1741-7007-9-75.

Kinkel MD, Prince VE. On the diabetic menu: zebrafish as a model for pancreas development and function. BioEssays. 2009;31:139-52. https://doi.org/10. 1002/bies.200800123

Kulkarni RN, Mizrachi E-B, Ocana AG, Stewart AF. Human $\beta$-Cell Proliferation and Intracellular Signaling. Driving in the Dark Without a Road Map. 2012;61: 2205-13. https://doi.org/10.2337/db12-0018.

Lam Pui-Ying PRT. Developing zebrafish disease models for in vivo small molecule screens. Curr Opin Chemical Biol. 2019;50:37-44. https://doi.org/10. 1016/j.cbpa.2019.02.005

Lee Y-S, Lee C, Choung J-S, Jung H-S, Jun H-S. Glucagon-Like Peptide 1 Increases $\beta$-Cell Regeneration by Promoting a- to $\beta$-Cell Transdifferentiation. Diabetes. 2018:67:2601-14. https://doi.org/10.2337/db18-0155.

Li M, Maddison LA, Crees Z, Chen W. Targeted overexpression of CKI-insensitive cyclin-dependent kinase 4 increases functional $\beta$-cell number through enhanced self-replication in zebrafish. Zebrafish. 2013;10:170-6. https://doi. org/10.1089/zeb.2012.0816.

Li M, Maddison LA, Page-McCaw P, Chen W. Overnutrition induces $\beta$-cell differentiation through prolonged activation of $\beta$-cells in zebrafish larvae. Am J Physiol-Endocrinol Metab. 2014;306:E799-807. https://doi.org/10.1152/ ajpendo.00686.2013.

Li M, Page-McCaw P, Chen W. FGF1 Mediates Overnutrition-Induced Compensatory $\beta$-Cell Differentiation. Diabetes. 2016;65:96-109. https://doi. org/10.2337/db15-0085.
Li Z, Korzh V, Gong Z. DTA-mediated targeted ablation revealed differential interdependence of endocrine cell lineages in early development of zebrafish pancreas. Differentiation. 2009;78:241-52. https://doi.org/10.1016/j. diff.2009.05.009.

Liu $\mathrm{H}$, et al. Intermittent fasting preserves beta-cell mass in obesity-induced diabetes via the autophagy-lysosome pathway. Autophagy. 2017;13:1952-68. https://doi.org/10.1080/15548627.2017.1368596.

Liu K-C, et al. Inhibition of Cdk5 Promotes $\beta$-Cell Differentiation From Ductal Progenitors. Diabetes. 2018;67:58-70. https://doi.org/10.2337/db16-1587.

Lu J, et al. IGFBP1 increases $\beta$-cell regeneration by promoting $\alpha$ - to $\beta$-cell transdifferentiation. EMBO J. 2016;35:2026-44. https://doi.org/10.15252/embj. 201592903.

Lynch SV, Pedersen O. The Human Intestinal Microbiome in Health and Disease. New Engl J Med. 2016;375:2369-79. https://doi.org/10.1056/NEJMra1600266.

Maddison LA, Chen W. Nutrient Excess Stimulates $\beta$-Cell Neogenesis in Zebrafish. Diabetes. 2012;61:2517-24. https://doi.org/10.2337/db11-1841.

Maddison LA, Joest KE, Kammeyer RM, Chen W. Skeletal muscle insulin resistance in zebrafish induces alterations in $\beta$-cell number and glucose tolerance in an age- and diet-dependent manner. Am J Physiol-Endocrinol Metab. 2015;308: E662-9. https://doi.org/10.1152/ajpendo.00441.2014.

Manfroid I, et al. Zebrafish sox9b is crucial for hepatopancreatic duct development and pancreatic endocrine cell regeneration. Developmental Biol. 2012;366:268-78. https://doi.org/10.1016/j.ydbio.2012.04.002.

Mezza T, et al. $\beta$-Cell Fate in Human Insulin Resistance and Type 2 Diabetes: A Perspective on Islet Plasticity. Diabetes. 2019;68:1121-9. https://doi.org/10. 2337/db18-0856

Moon JH, et al. Serotonin Regulates Adult $\beta$-Cell Mass by Stimulating Perinatal $\beta$-Cell Proliferation. Diabetes. 2020;69:205-14. https://doi.org/10.2337/db19-0546.

Moss JB, et al. Regeneration of the Pancreas in Adult Zebrafish. Diabetes. 2009;58: 1844-51. https://doi.org/10.2337/db08-0628.

Ninov N, Borius M, Stainier DYR. Different levels of Notch signaling regulate quiescence, renewal and differentiation in pancreatic endocrine progenitors. Development (Cambridge, England). 2012;139:1557-67. https://doi.org/10. 1242/dev.076000

Ninov N, et al. Metabolic Regulation of Cellular Plasticity in the Pancreas. Curr Biol. 2013;23:1242-50. https://doi.org/10.1016/j.cub.2013.05.037.

Noèlia T, Eduard M. Gastrin induces ductal cell dedifferentiation and $\beta$-cell neogenesis after 90\% pancreatectomy. J Endocrinology. 2014;223:67-78. https://doi.org/10.1530/JOE-14-0222.

Pack $M$, et al. Mutations affecting development of zebrafish digestive organs. Development. 1996;123:321-8.

Pagliuca FW, et al. Generation of functional human pancreatic $\beta$ cells in vitro. Cell. 2014;159:428-39. https://doi.org/10.1016/j.cell.2014.09.040.

Parsons JA, Brelje TC, Sorenson RL. Adaptation of islets of Langerhans to pregnancy: increased islet cell proliferation and insulin secretion correlates with the onset of placental lactogen secretion. Endocrinology. 1992;130: 1459-66. https://doi.org/10.1210/endo.130.3.1537300.

Parsons MJ, et al. Notch-responsive cells initiate the secondary transition in larval zebrafish pancreas. Mechanisms Dev. 2009;126:898-912. https://doi.org/10. 1016/j.mod.2009.07.002.

Pauls S, Zecchin E, Tiso N, Bortolussi M, Argenton F. Function and regulation of zebrafish nkx2.2a during development of pancreatic islet and ducts. Dev Biol. 2007;304:875-90. https://doi.org/10.1016/j.ydbio.2007.01.024.

Perl S, et al. Significant Human $\beta$-Cell Turnover Is Limited to the First Three Decades of Life as Determined by in Vivo Thymidine Analog Incorporation and Radiocarbon Dating. J Clin Endocrinology Metab. 2010;95:E234-\. https:// doi.org/10.1210/jc.2010-0932.

Pisharath H, Rhee JM, Swanson MA. Leach, S. D. \& Parsons, M. J. Targeted ablation of beta cells in the embryonic zebrafish pancreas using E. coli nitroreductase. Mechanisms Development. 2007;124:218-29. https://doi.org/ 10.1016/j.mod.2006.11.005.

Pothineni NV, M. J. Follow-up of Glycemic Control and Cardiovascular Outcomes in Type 2 Diabetes. New England J Med. 2015;373:977-8. https://doi.org/10. 1056/NEJMc1508386.

Rawls JF, Samuel BS, Gordon JI. Gnotobiotic zebrafish reveal evolutionarily conserved responses to the gut microbiota. Proc Nat Acad Sci United States America. 2004;101:4596-601. https://doi.org/10.1073/pnas. 0400706101.

Rezania A, et al. Maturation of Human Embryonic Stem Cell-Derived Pancreatic Progenitors Into Functional Islets Capable of Treating Pre- 
existing Diabetes in Mice. Diabetes. 2012;61:2016-29. https://doi.org/10 2337/db11-1711.

Rovira M, et al. Chemical screen identifies FDA-approved drugs and target pathways that induce precocious pancreatic endocrine differentiation. Proc Nat Acad Sci. 2011;108:19264-9. https://doi.org/10.1073/pnas. 1113081108.

Schulz N, et al. Critical role for adenosine receptor A2a in $\beta$-cell proliferation. Mol Metab. 2016;5:1138-46. https://doi.org/10.1016/j.molmet.2016.09.006.

Shapiro AM. Islet transplantation in seven patients with type 1 diabetes mellitus using a glucocorticoid-free immunosuppressive regimen. N Engl J Med. 2000;343.

Shen W, et al. Small-Molecule Inducer of $\beta$ Cell Proliferation Identified by HighThroughput Screening. J Am Chem Soc. 2013;135:1669-72. https://doi.org/10. 1021/ja309304m.

Singh SP, et al. Different developmental histories of beta-cells generate functional and proliferative heterogeneity during islet growth. Nature Communications. 2017:8:664. https://doi.org/10.1038/s41467-017-00461-3.

Stamateris RE, Sharma RB, Hollern DA, Alonso LC. Adaptive $\beta$-cell proliferation increases early in high-fat feeding in mice, concurrent with metabolic changes, with induction of islet cyclin D2 expression. Am J Physiology Endocrinol Metab. 2013;305:E149-59. https://doi.org/10.1152/ ajpendo.00040.2013.

Stewart AF, et al. Human $\beta$-Cell Proliferation and Intracellular Signaling: Part 3. Diabetes. 2015;64:1872-85. https://doi.org/10.2337/db14-1843.

Swenne I. Effects of Aging on the Regenerative Capacity of the Pancreatic B-Cell of the Rat. Diabetes. 1983;32:14. https://doi.org/10.2337/diab.32.1.14.

Teta M, Rankin MM, Long SY, Stein GM, Kushner JA. Growth and Regeneration of Adult $\beta$ Cells Does Not Involve Specialized Progenitors. Developmental Cell. 2007;12:817-26. https://doi.org/10.1016/j.devcel.2007.04.011.

Thorel F, et al. Conversion of adult pancreatic a-cells to $\beta$-cells after extreme $\beta$ cell loss. Nature. 2010;464:1149-54. https://doi.org/10.1038/nature08894.

Togashi Y, et al. $\beta$-Cell Proliferation After a Partial Pancreatectomy Is Independent of IRS-2 in Mice. Endocrinology. 2014;155:1643-52. https://doi.org/10.1210/en. 2013-1796.

Toselli $C$, et al. Contribution of a non- $\beta$-cell source to $\beta$-cell mass during pregnancy. PloS one. 2014;9:e100398. https://doi.org/10.1371/journal.pone. 0100398.

Tremmel DM, Mitchell SA, Sackett SD, Odorico JS. Mimicking nature-made beta cells: recent advances towards stem cell-derived islets. Curr Opin Organ Transplant. 2019;24:574-81. https://doi.org/10.1097/MOT.0000000000000687.

Tsuji $\mathrm{N}$, et al. Whole organism high content screening identifies stimulators of pancreatic beta-cell proliferation. PloS One. 2014;9:e104112. https://doi.org/ 10.1371/journal.pone.0104112.

Wang, G. et al. First quantitative high-throughput screen in zebrafish identifies novel pathways for increasing pancreatic $\beta$-cell mass. elife 4, e08261, doi: https://doi.org/10.7554/eLife.08261 (2015).

Wang Y, Rovira M, Yusuff S, Parsons MJ. Genetic inducible fate mapping in larval zebrafish reveals origins of adult insulin-producing $\beta$-cells. Development. 2011;138:609-17. https://doi.org/10.1242/dev.059097.

Weir GC, Bonner-Weir S, Leahy JL. Islet Mass and Function in Diabetes and Transplantation. Diabetes. 1990;39:401-5. https://doi.org/10.2337/diab. 39.4.401.

Xu J, Cui J, Del Campo A, Shin CH. Four and a Half LIM Domains 1b (Fhl1b) Is Essential for Regulating the Liver versus Pancreas Fate Decision and for $\beta$ Cell Regeneration. PLOS Genet. 2016;12:e1005831. https://doi.org/10.1371/ journal.pgen.1005831.

$\mathrm{Xu}$ J, et al. Inhibition of TBK1/IKKE Promotes Regeneration of Pancreatic $\beta$-cells. Sci Rep. 2018;8:15587. https://doi.org/10.1038/s41598-018-33875-0.

Yamamoto J, et al. Neuronal signals regulate obesity induced $\beta$-cell proliferation by FoxM1 dependent mechanism. Nature Commun. 2017;8:1930. https://doi. org/10.1038/s41467-017-01869-7.

Yang $B$, et al. Depletion of insulin receptors leads to $\beta$-cell hyperplasia in zebrafish. Science Bulletin. 2017

Ye L, Robertson MA, Hesselson D, Stainier DYR, Anderson RM. Glucagon is essential for alpha cell transdifferentiation and beta cell neogenesis. Development (Cambridge, England). 2015;142:1407-17. https://doi.org/10. 1242/dev.117911.

Ye L, Robertson MA, Mastracci TL, Anderson RM. An insulin signaling feedback loop regulates pancreas progenitor cell differentiation during islet development and regeneration. Dev Biol. 2016:409:354-69. https:// doi.org/10.1016/j.ydbio.2015.12.003.

\section{Submit your manuscript to a SpringerOpen ${ }^{\circ}$ journal and benefit from:}

- Convenient online submission

- Rigorous peer review

- Open access: articles freely available online

High visibility within the field

- Retaining the copyright to your article

Submit your next manuscript at $\boldsymbol{\nabla}$ springeropen.com 